\title{
A estética da degeneração e a expressão dos alienados: leituras de Júlio Dantas no Hospital de Rilhafoles
}

\section{The aesthetics of degeneration and expressions of the alienated: readings from Júlio Dantas at the Rilhafoles Hospital}

\author{
Stefanie Gil Franco \\ Doutoranda em História da Arte, Faculdade de Ciências \\ Sociais e Humanas/Universidade Nova de Lisboa. \\ Avenida de Berna, 26-C \\ 1069-061 - Lisboa - Portugal \\ steffranco@gmail.com
}

Recebido para publicação em março de 2016.

Aprovado para publicação em setembro de 2016.
FRANCO, Stefanie Gil. A estética da degeneração e a expressão dos alienados: leituras de Júlio Dantas no Hospital de Rilhafoles. História, Ciências, Saúde Manguinhos, Rio de Janeiro, v.24, n.3, jul.-set. 2017, p.727-744.

\section{Resumo}

A proposta é apresentar, brevemente, o modo como as expressões artísticas dos alienados surgem como elemento discursivo na leitura médica e crítica de Júlio Dantas, tendo como ponto de partida sua tese, Pintores e poetas de Rilhafolles, apresentada, em 1900, como conclusão do curso de medicina, em Lisboa. Trata especialmente da averiguação dos métodos utilizados por Dantas em suas investidas e proposições conceituais sobre essa temática, considerando que seus interesses iam ao encontro de questões muito específicas: as características e as formas da degeneração social. O artigo também propõe a revisão de algumas das reverberações nos meios sociais e artísticos provocadas pela publicação da tese.

Palavras-chave: Júlio Dantas (1876-1962); arte; loucura; degeneração; Portugal.

\section{Abstract}

The proposal of this article is to briefly present how artistic expressions of the alienated appear as a discursive element in medical and critical readings of Júlio Dantas, starting with his thesis, Pintores e poetas de Rilhafolles, which he presented in 1900 as the conclusion to his medicine course in Lisbon. This particularly involves investigating the methods Dantas used in his invested and conceptual propositions on this topic, considering that his interests responded to very specific issues: the characteristics and forms of social degeneration. The article also reviews some of the reverberations in the social and artistic environments that were insulted by the publication of the thesis.

Keywords: Júlio Dantas (1876-1962); art; madness; degeneration; Portugal. 
Evidentemente, do artista louco pode esperar-se mais do que do louco artista. O que não quer dizer que se deva esperar muito.

Júlio Dantas

Uma das propostas deste artigo é descrever uma controvérsia que se estendeu a partir da publicação da tese Pintores e poetas de Rilhafoles (1900), defendida pelo doutor Júlio Dantas (1876-1962), em Portugal. É inegável a importância dessa tese: trata-se da primeira análise sistematizada de obras (pinturas, desenhos e textos) de pacientes alienados em Portugal e uma das primeiras de que se tem notícia na Europa; insere-se num momento em que a psiquiatria portuguesa é embrionária, e extremamente importante na promoção de categorias e nosologias ainda pouco reconhecidas, assim como no processo de institucionalização da especialidade no país; revela o discurso de intervenção social de Dantas, cujo objetivo era atuar como alienista social, em defesa da sociedade contra os males da alienação - neste ponto, veremos que foram muitas as reverberações e os contornos insultados pela tese e por seu autor junto à sociedade da época e, em especial, junto aos artistas modernistas portugueses.

Este artigo é desenvolvido em duas partes complementares: na primeira, a tese de Dantas, Pintores e poetas de Rilhafoles, é analisada em sua própria intencionalidade, ou seja, em seus termos e em sua problematização; na segunda, a análise é feita de acordo com o contexto histórico em que foi escrita - compreendendo os diálogos que o autor trava (direta e indiretamente) e, principalmente, buscando relações entre o texto e o modo como as expressões dos alienados eram concebidas dentro do saber médico, artístico e social da época. É interessante, por ora, notar que Dantas formou-se em medicina pela Escola Médico-Cirúrgica de Lisboa quando ainda era muito jovem e concluiu sua tese, no Hospital de Rilhafoles ${ }^{1}$ - o primeiro construído em Portugal para os cuidados dos "alienados" -, sob a orientação do doutor Miguel Bombarda² (1851-1910). Em nota autobiográfica, escrita em 1925, Dantas elucidava a importância e a atualidade de sua tese:

Completei o curso médico em 1899, com 23 anos; e um ano depois, em 6 de Julho de 1900, fiz acto-grande, defendendo, nemine discrepante, a minha tese sobre as manifestações artísticas dos loucos: Pintores e poetas de Rilhafolles. De quanta gente conhecida eu teria de falar, se escrevesse agora este livro! (Dantas, 1925). ${ }^{3}$

Segue, explicitando que, apesar de sua formação, nunca atuou em clínica profissional, mas manteve um ininterrupto interesse pelos "assuntos médicos", o que tornou "cheia de medicina a [sua] obra literária" (Dantas, 1925). Dantas, ao formar-se em medicina, inseria-se num debate ainda em formação sobre o amparo e o cuidado dos alienados, mas, acima de tudo, acerca da defesa da sociedade contra os males que levavam à degeneração de um povo, como veremos no desenvolvimento deste texto. Com isso, torna-se, junto a outros médicos alienistas, uma das principais referências ao se tratar da institucionalização psiquiátrica em Portugal.

Ao longo da vida, Dantas publicou uma série de livros de versos, teatro e prosa, deixando de vez a prática médica e tornando-se mais conhecido e reverenciado como "polígrafo". Além disso, acumulou títulos políticos em ministérios e foi embaixador de Portugal no Brasil entre 1941 e 1949. Nesse processo, reuniu admiradores e inimigos, e suscitou controvérsia tanto 
entre os artistas modernistas como entre os colegas de medicina. Adiante, veremos outros feitos de Dantas, além de contextualizá-lo no cenário português, tornando-o mais familiar aos leitores. ${ }^{4}$

\section{Os pintores e poetas de Rilhafoles}

Pintores e poetas de Rilhafoles (Dantas, 1900, p.1) tem como objetivo "o estudo d'algumas características da arte do louco, pela vantagem que da sua fixação resulta para a crítica geral da arte sã e pela importância que esse estudo reveste na diagnose de certas formas de loucura". Com isso, Dantas buscava balizar os territórios da "arte sã" e da "estranha e monstruosa arte dos manicômios" (p.3), objetivando uma dupla proposição: primeiro, a salvaguarda social - o que corroboraria para a criação de medidas profiláticas de contenção de doenças degenerativas - e, segundo, a compreensão e a diagnose dessas próprias doenças, já em âmbito hospitalar. Além disso, para Dantas, sua profissão possuía uma responsabilidade social com a arte em geral. Sendo o médico o profissional com capacidade intelectual de compreender a arte do louco, era também, na visão do autor, o responsável por compreender a arte do homem normal para, enfim, separá-las em âmbito social: a arte louca no hospício, em tratamento e isolamento social, e a arte sã nos museus e em contato com o público. Nesse sentido, o médico teria um importante papel na crítica de arte, afinal "é estudando a arte malsana que se aprende a ver a arte sadia" (p.13).

O texto deixa claro, logo de início, o papel do médico como o de um intelectual, antes mesmo de ser um conhecedor das enfermidades, sobretudo porque as doenças da mente seriam os piores males sociais, aquilo que poderia desolar a humanidade se não fosse conhecido, tratado e sanado. O médico intelectual atento a tais defeitos poderia não apenas tratar pacientes, mas curar a sociedade. Dantas enxergava nas obras dos pacientes de Rilhafoles, assim, um importante material de análise estética, em especial pelo tom degenerativo que as formas expressas possuíam. Nesses termos, nos poemas e pinturas haveria uma série de características emblemáticas que poderiam ser agrupadas e classificadas de acordo com os tipos de alienação. Para tanto, propõe criar uma taxionomia a partir do método comparativo de associação das formas e características similares entre as expressões dos alienados e as dos artistas em geral. Estendendo tais classificações para um âmbito mais amplo das artes, o médico poderia, portanto, visualizar determinados tipos doentios na sociedade, empregando tratamentos e medidas profiláticas de contenção desses males. Assim, seus interesses iriam da arte hospitalar para a arte museológica, método muito comum em sua época: partir do mais "simples" para compreender o mais "complexo". A medicina, com esse papel taxionômico das artes dos alienados, teria, portanto, seu papel na crítica da arte em geral, considerando: "O seu admirável poder de díffusão, que lhe permittiu invadir os limites da literatura, da arte, da sociologia, da história, do direito e da política". Sobre isso, conclui: "Do estudo das manifestações artísticas nas degenerescências psychicas há a esperar um largo desenvolvimento da philosophia da arte" (Dantas, 1900, p.2-3).

Dantas é veemente ao discordar da ideia trivial de que "de louco todo artista tem um pouco", ou, em suas palavras: "O preconceito leigo de que não há grande poeta ou grande pintor que não tenha 'aduela de menos' poderia dar margem a que se esperassem preciosidades 
da arte de Rilhafoles" (Dantas, 1900, p.7). Não há para ele nenhum tipo de valor estético na obra dos pacientes alienados, e, se realmente há alguma importância nessas expressões, são apenas de uso médico e profilático - o que se justifica pela falta de destreza técnica, de bases acadêmicas e de cultivo profissional. Em alguns pacientes, faz notar uma predisposição para as coisas da arte, mas deixando claro que a doença, quando em estado desenvolvido, rompe os laços do sujeito com a expressão: "É sol de pouca dura" (p.8). A manifestação artística dos alienados é, conforme o discursar de Dantas, uma extensão da própria doença, ou seja, as pinturas ou poemas de Rilhafoles estão em relação de contiguidade ao diagnóstico do paciente, pois neles não há razão, há apenas debilidade. Assim, o doente representa a si mesmo dentro da sua expressão, considerando que não pode expurgar-se daquilo que já degenerou: "O doente passa a ser, dentro da sua arte, a caricatura de si mesmo ... Deixa de ser uma arte o que nós vemos, para tornar-se a expressão pictural d'um desvio ideativo" (p.8-9).

Não caberia aqui repassar, caso a caso, os descritivos que Dantas faz a partir da classificação dos tipos doentes. O que se ressalta em sua análise é que, em uma escala degenerativa da mente, os escritores eram poucos, pois as letras exigem um alto grau de intelectualidade, enquanto os "graphonomos" e, em seguida, os pintores aumentavam consideravelmente. Mas, mesmo nesses últimos, conforme Dantas, havia um acentuado grau de simbolismos:

No grosso da documentação de Rilhafolles há de tudo, desde as largas composições de caracter religioso, imagens de bispos em nichos d'oiro, evocações evangélicas, formulas litúrgicas, - até as mais simples expressões figuradas que certos loucos nos dão como exteriorisação plástica dos seus delirios, systematisados ou não, e que lembram, pela maior parte, as figurações da tatuagem vulgar, as marcas e as chrismas, tão canhestras no traço e tão originaes no symbolo, em que são useiros e veseiros os portuguezes (Dantas, 1900, p.10).

É partindo dessa classificação da arte dos insanos que Dantas insistentemente nos lembra que o médico conhecedor das anomalias mentais deve ensinar à crítica de arte sobre a diferença entre as "características e extravagâncias" do paranoico e a "originalidade do gênio". Sobretudo, carrega em seu discurso a

amplidão do conceito anthropologico dos psychiatras italianos (paranoia indiferente, paranoia sine-delirio) [que] rompe os muros dos manicomios e alastra cá, por fora, dando os revolucionários, os anarchistas, os mattoides, os santos, e toda essa galeria de figuras de cêra da litteratura e da arte decadente, a que é de uso chamar symbolistas, mysticos, néogothicos, bysantinos, préraphaelitas, e vários outros nomes de giria barbara creados com peor ou melhor fortuna pelos pseudo-genios da Dissolução (Dantas, 1900, p.11-12).

Entre os italianos, essa passagem nos remete diretamente a Césare Lombroso (1835-1909), que, em sua teoria sobre o "gênio e a loucura", considerava que o "gênio é uma degenerescência de natureza epiléptica" (Cebola, 1906, p.163). Nesses termos, os homens de feitos extraordinários estariam ligados a um tipo de inspiração proveniente do inconsciente ou da relação entre a "instantaneidade" e a "inconsciência" (p.166). Aqui, optou-se por citar Lombroso por intermédio da obra de Luís Cebola (1876-1967)5 e, assim, acompanhar o modo como essas práticas e teorias chegaram a Portugal. Em 1906, Cebola publica a tese A mentalidade dos epilépticos, também sob a orientação de Bombarda, na qual analisa os 
desenhos e, principalmente, os escritos de internos de Rilhafolles no intuito de localizar nessas expressões algumas características que as unissem em um tipo mental, considerando atributos como "forma" e "conteúdo". Cebola, ao final da tese, elucida uma crítica a Lombroso, concluindo que: "O maior erro dos lombrosianos provém de assemelharem a inspiração ... com qualificativos subitaneo e inconsciente aos homens extraordinários" (p.168). Ou seja, para Cebola, o gênio não necessariamente é um homem com virtudes excepcionais, dotado de inspirações "instinctivas", mas um sujeito que "não desvia da evolução normal: apenas marcha na vanguarda" (p.171). Dantas não faz grandes considerações sobre essa questão, mas deixa-nos subtendidas suas leituras e opções teóricas; não há referências que levem a um debate entre ele e Cebola, nem ao menos citações de um ao outro. Dada a proximidade do objeto de suas teses e o fato de ambas terem sido orientadas por Bombarda, é provável que se conhecessem, mas não podemos tirar dessas ocorrências grandes conclusões, a não ser o fato de que teorias como as de Lombroso andavam às voltas no pensamento da época e, mais do que isso, incitavam o interesse dos médicos pelas expressões dos alienados. Por ora, é preciso perceber que a insistência de Dantas em garantir um terreno médico ao lado da crítica de arte tem um grande propósito não apenas ideológico, mas, principalmente, político. Dantas buscava investir seus conhecimentos em âmbito social, o que não é de admirar; afinal em seu discurso está contido todo o conhecimento de uma época em que o médico psiquiatra estava mais para um alienista social do que para um doutor de gabinete.

\section{O alienista social e a teoria da degeneração}

O livro de Dantas é dedicado ao professor Miguel Bombarda com "a expressão de agradecimento e admiração" (Dantas, 1900). Bombarda foi o médico que iniciou uma coleção de desenhos, pinturas e escritos dos pacientes do Hospital de Rilhafoles, de cunho totalmente inovador no cenário português. É provável que essa "documentação" 6 tivesse para o médico o valor do apontamento psiquiátrico em convergência com a teoria de Dantas: em nada se buscava justificar nas obras um valor estético e muito menos artístico-social. Bombarda não escreveu sobre as obras, e há poucos testemunhos que narrem a existência e a proporção dessa documentação. O jornal O Dia, em uma edição de 1902, traz uma breve reportagem, intitulada "Miseria em Lisboa", sobre a situação do hospital e retrata a sala em que Bombarda guardava as obras dos pacientes (chamando-a mesmo de "museu"):

Vemos alli de tudo: plantas de balões dirigíveis e de habitações nos pólos, vestuários de palha tecida, mappas de payzes mysteriosos, etc. Prendem-nos a atenção alguns desenhos a pastel, bons, deixando comtudo a descoberto a nota da loucura ... Há também, d'um outro auctor, uma Ceia de Apóstolos, que lembra muito de longe, pelo primitivo desenho e pelos tons demasiados, os quadros bíblicos de Puvis de Chavannes, mas, é escusado insistir n'isto, a Ceia do museu de Rilhafoles não tem sciencia nenhuma de planos e perspectivas, nem manifesta talento; vê-se que é feita por um artista inculto (Miséria..., 5 set. 1902, p.2).

Cronologicamente, essa coleção do Hospital de Rilhafoles pode ser considerada uma das primeiras voltada para as expressões plásticas de pacientes psiquiátricos que existiu na Europa. Dantas chega a mencionar, logo no início de sua tese, a escassez bibliográfica, que lhe impõe 
a criação de uma estrutura analítica própria. Diz, ainda, ter conhecimento de apenas um artigo publicado em 1899 no The American Journal of Insanity de autoria de Ales Hrdlicka ${ }^{7}$ que, segundo ele, buscou analisar as "manifestações d'arte no campo da mentalidade anormal" (Dantas, 1900, p.2). Não resta dúvida de que, para o contexto português, uma pesquisa com os objetivos de Dantas - ao lado da coleção iniciada por Bombarda - era realmente de cunho inovador.

O método comparativo em psicologia a partir das expressões produzidas por doentes em estado de internação surge, pode-se dizer, em meados do século XIX com as pesquisas de Pliny Earle (1844), nos EUA, e de Forbes Winslow (1848), na Inglaterra - ambas buscando compreender o que havia em comum nas expressões dos alienados entre si, ou melhor, o que podia ser retratado em termos de diagnóstico nas imagens produzidas pelos doentes. Mais tarde, o francês Ambroise Tardieu (1880) e o alemão Max Simon (1876) também realizaram pesquisas de cunho comparativo sobre a estética dos alienados, agregando classificações e estreitando conhecimentos. ${ }^{8}$ Conforme bem retrata o pesquisador Arley Andriolo, em seu texto sobre o método comparativo na origem da psicologia da arte:

Nessa primeira visada médica sobre a obra de 'doentes mentais', a proposição preponderante dizia respeito à obra como um registro sintomático. A partir desses autores, manifestações artísticas de internos de hospitais psiquiátricos elevam-se à condição de documento clínico, possibilitando ao médico competente, por meio delas, delimitar o tipo de delírio e diagnosticar seus pacientes (Andriolo, jun. 2006).

Se Dantas tinha ou não conhecimento de tais pesquisas, não compete a este artigo questionar. Fato é que em seu discurso está embutida toda a teoria da degeneração, ${ }^{9}$ que constitui, por assim dizer, o terreno de interesses nas obras dos alienados naquele momento. O próprio Bombarda (1898, p.66-68) é quem nos faz uma breve definição dessa teoria:

As degenerescências, progressivas ou regressivas, abrangem múltiplos estados de anomalia cerebral, desde as formas geniais, passando pelas nevroses, pela loucura, e pelo crime, até ao idiotismo. E o que é mais, é que essas ligações não se reconhecem só aprés coup, depois das manifestações, depois dos actos, mas ainda se descobrem no indivíduo, até no momento do nascimento, pelas anomalias de forma que constituem o que se chamam estigmas físicos de degenerescência.

Considerando que o asilo nasce em meados do século XVIII como uma maneira de coibir a proliferação dos males que impediriam o progresso social, ou, em outros termos, como forma de libertar o organismo social do obstáculo da degeneração, vemos nas palavras de Bombarda a exata construção de uma teoria social da loucura em Portugal. Nesse momento, a nascente ciência da alienação vê como necessário encarcerar para não contaminar; prevenir para não proliferar; conhecer para não escapar; classificar para não confundir. Em artigo publicado na Revista Brasil Portugal, Bombarda $(1899$, p.3) afirma sobre a necessidade de se tratar dos alienados como uma maneira racional para os povos entrarem em um sentido de civilização e conclui: "Portugal ocupa precisamente o logar da sua civilização". ${ }^{10}$

Está nas palavras de Bombarda e na tese de Dantas a atitude do alienista social, que, em sua prática diária, deveria conhecer a loucura em todos os seus meios, tais como as "ervas daninhas" que nascem e se proliferam de maneira indesejada e colocam em risco o resto da 
vegetação. ${ }^{11} \mathrm{O}$ que estava em jogo era a ciência médica como aquela que poderia, por meio de suas pesquisas, produzir uma nação em consonância com a biopolítica:12 que tipos de indesejados fariam entorpecer a nação? A internação, como narra a professora Ana Leonor Pereira (1986, p.86), era considerada

o imperativo do instinto de conservação da espécie e uma exigência iniludível da virtude pública fundadora da harmonia social e do progresso da civilização ... O internamento apenas institucionalizava um estado de facto pois não era possível privar de liberdade aquele que não a possuía. Ao ser internado o louco nada perdia e a sociedade lucrava sob o ponto de vista orgânico, econômico e social.

Mas não bastava internar. A alienação estreitava cada vez mais os laços com a sociedade, tornando-a improdutiva e atrasando seu progresso, por isso via-se como necessário, para além de encarcerar, conhecer as degenerescências em seus vários estágios, em suas várias características e diagnoses. Dantas, em consonância com as teorias de sua época, via a causa da doença mental na hereditariedade, tal como descreve o doutor Júlio de Matos (1856-1922) ${ }^{13}$ em seu Manual das doenças mentais: "Segundo este modo de ver, o alienado representa, não a repetição necessária da loucura ancestral, mas o último termo de uma longa série de íntimas degenerações físicas e psicológicas" (Matos, 1884, p.14-15). Considerando tais argumentos, a preocupação de Dantas em categorizar as expressões dos alienados e encontrar vestígios dela na arte produzida fora dos hospitais encontra justificativa. Afinal, para o médico, essas expressões, assim como as formas mais arraigadas de manifestação da doença, denunciavam uma hereditariedade degenerativa. Em outras palavras, a relação direta entre determinados tipos estéticos provava a Dantas que muitos dos artistas, tidos como "sadios", eram na verdade detentores de caracteres degenerativos. Por isso, ele tanto enfatiza a importância do caráter intelectual da medicina: é preciso conhecer de estética, de palavra, de formas e de conteúdo das artes para distinguir socialmente um louco de um homem de talento.

A hereditariedade é a chave para compreender a teoria de Dantas acerca das expressões dos alienados. O caráter regressivo das doenças tornaria toda a humanidade degenerada, se não fosse erradicado com medidas profiláticas e de contenção. Decerto, a teoria lamarckiana entrou com força em Portugal e tornou essas afirmativas mais consistentes. Segundo ela, a herança e a transformação das espécies caminham juntas, ou seja, conforme a tese defendida pelo francês Chevalier de Lamarck, a hereditariedade estaria associada a características adquiridas pelo meio, e dessa forma os fatores sociais teriam uma influência direta na degeneração (ver Quintais, 2008). Se fatores sociais são associativos a causas degenerativas hereditárias, a arte deve estar sã, pois é ela uma das grandes responsáveis pelas mentalidades sociais:

é pela decadência artística que se mede o estado de dissolução d'uma raça ou dum povo. No início das psychoses orgânicas são os sentimentos estheticos os primeiros que desapparecem. Em ponto grande, dá-se o mesmo nas raças: é pela arte que ellas principiam a morrer (Dantas, 1900, p.15).

Nas últimas páginas - após debruçar-se detidamente sobre diversas característíscas nosológicas das expressões dos loucos -, Dantas retoma esse argumento arrematando que:

Da fixação destas características e do seu estudo acima feito resulta uma desconsoladora verdade: a de que as viciações que ferem a arte do louco apparecem por egual na litteratura, 
na arte consagrada, bem as claras, marcando a obra de muito decadente que empunha com ar pontifício a cabuta luminosa de 'pastor de escola' (Dantas, 1900, p.47). ${ }^{14}$

Essa conclusão leva a crer que, para Dantas, a sociedade já estava em vias de degenerar-se; prova disso eram as inúmeras obras com caráter "decadente" em meio à arte consagrada. Se a crítica de arte não fosse conhecedora da alienação social, a "verdadeira" arte estaria fadada ao fim, por isso afirma: "É preciso ensinar a crítica de arte a criticar-nos", pois esta não sabe distinguir "a arte pura do desvio degenerativo" (Dantas, 1900, p.49-50).

Considerando que nesse período houve um crescimento substancial de métodos e instrumentos de biopolítica a fim de tornar visíveis as degenerescências sociais, Dantas enxergava, também, a necessidade de criar artifícios para salvaguardar os campos estético e artístico. A má estética deveria ser contida anteriormente a sua manifestação, reconhecendo os tipos degenerados e empregando a eles medidas profiláticas. Em outras palavras, algumas características estéticas seriam sintomas ou manifestações da degenerescência e deveriam ser evitadas para não corromper outros tipos sociais. Afinal, seguindo a tese lamarckiana: a degeneração opera por contágio.

Dantas mostra, mesmo antes da publicação de sua tese, que conceber os "typos sociais" era importante para a criação de uma sociedade forte, sadia e próspera. A publicação de 1897, em parceria com o também médico e escritor Manoel Penteado, Doentes: estudos, é um exemplo típico das intenções de Dantas. Os autores fazem uma análise de alguns "doentes" a partir de pequenos textos literários, a que dão títulos como "Arco-íris", "O almoço", "As pudicas", "A virgem estrábica", "O choreiro", entre outros. Mas esse não é apenas um livro de contos: é um livro que delineia os tipos desmoralizados da sociedade, escrito por dois médicos, em linguagem popular. Ao início, no antelóquio, os autores delimitam o que pretendem e não pretendem com o livro: "Cuidamos d'algumas figuras complexas de doentes, de desviados, máscaras e celebrações stygmatisadas por accumulação de taras degenerativas" (Dantas, Penteado, 1897, p.XIII-XIV). Em todo o índice, desenham-se tipos sociais: no pequeno conto "O doido", por exemplo, os autores descrevem as características físicas e mentais do personagem: "É muito alto, de larga envergadura superior, e tem uma pequena gibba a curvar-lhe o thorax ossudo ... A cabeça é assymetrica: craneo achatado n'um dos parietais, alevantando-se em grande bossa no outro; face descahida a uma banda, porque da outra lhe falta o maxilar superior" (p.9-10). Em "Rosita", outro exemplo, o caso tratado é o da mulher com perturbações emocionais: "Rosita teve sempre má vontade às alegrias. Só em chorando é que estava bem". Ao que a moça conclui: "Eu sempre cuidei que depois d'um contentamento vinha logo uma desgraça ... Não quero ser alegre para não ser triste ao depois" (p.3-6). E prosseguem, delimitando outros tipos, definindo-os em: desvios sexuais femininos, alcoolismo, deformações cranianas, corporais, de caráter e de conduta social, e assim por diante.

Delinear esses tipos degenerados em linguagem acessível a todo o organismo social a partir desses pequenos contos é, por certo, uma atitude política e característica de um cientista como Dantas, pois sai do discurso médico, especializado, e enraíza-se na mentalidade social. Para atingir o tipo comum da sociedade era necessário, portanto, sair do artigo médico e investir numa literatura de intervenção social. O livro é pequeno, cabe num bolso, os contos não ultrapassam as três páginas e possuem linguagem simples e anedótica, ao gosto da época, mas 
é certeiro no que se propõe: descrever e delinear os indesejados da sociedade, a degradação de uma época, os tipos malfazejos.

A professora Ana Leonor Pereira (1986, p.95) faz uma reflexão sobre o que foi abordado: "A figura do alienista é contemporânea à do alienado e se é verdade que o hospital fabricava alienados, mais seguro ainda é que produzia alienistas". Dantas queria produzir alienistas sociais para além dos hospitais, queria homens capazes de distinguir, entre as artes, o que deveria ser encaminhado ao museu e o que deveria ser encaminhado à casa de alienados. Eis mais uma forma de salvar a humanidade da degeneração.

\section{A arte em tempos de alienação social}

A ideia deste texto foi, até agora, a de dar voz a Júlio Dantas por meio de sua própria produção, e não das críticas que lhe foram atribuídas anos mais tarde. Afinal, hoje, sabe-se mais de Dantas por Almada Negreiros (1893-1970 $)^{15}$ do que pelo próprio Dantas. Se o médico literato propunha em sua tese alcançar a crítica de arte para que esta se fortificasse contra a degeneração estética, foi em especial com o artista futurista que atingiu maior repercussão. Em junho de 1916, à moda da época, Negreiros (2013) publica o Manifesto anti-Dantas e por extenso por José de Almada Negreiros poeta d'Orpheu futurista e tudo!, meses após a estreia de Sóror Mariana - peça escrita por Dantas - no Teatro Ginásio de Lisboa, destilando uma acalorada resposta ao médico. O manifesto dedica longos parágrafos a analisar, em tom de severas críticas, a peça teatral e, vale ressaltar, não menciona a tese Pintores e poetas de Rilhafoles. O alvo de Negreiros parece ser especificamente o Dantas literato, o Dantas que tudo sabia e que sobre tudo queria saber:

CONTINUE O SENHOR DANTAS A ESCREVER ASSIM QUE HÁ-DE GANHAR MUITO CO'O ALCUFURADO E HÁ-DE VER, QUE AINDA APANHA UMA ESTÁTUA DE PRATA POR UM OURIVES DO PORTO, E UMA EXPOSIÇÃO DAS MAQUETES PR'O SEU MONUMENTO ERECTO POR SUBSCRIÇÃO NACIONAL DO SÉCULO A FAVOR DOS FERIDOS DE GUERRA, E A PRAÇA DE CAMÕES MUDADA EM PRAÇA DO DR. JULIO DANTAS, E COM FESTAS DA CIDADE P'LOS ANNIVERSARIOS, E SABONETES EM CONTA «UULIO DANTAS», E PASTA DANTAS P'ROS DENTES, E GRAXA DANTAS P'RAS BOTAS, E NIVÉINA DANTAS, E COMPRIMIDOS DANTAS, E AUTOCLISMOS DANTAS E DANTAS, DANTAS, DANTAS, DANTAS... E LIMONADAS DANTAS-MAGNÉSIA (Negreiros, 2013).

E por diversas vezes aclama pela morte de Dantas: "MORRA O DANTAS, MORRA! PIM!" (Negreiros, 2013). Matando Dantas, Negreiros também propunha que morressem todos os que de certa forma andavam em rumos contrários ao dos futuristas e de suas novas propostas artísticas ou, ainda, aqueles que representavam um certo "decadentismo" tanto na crítica como na própria arte portuguesa: "E OS JORNALISTAS DO SÉCULO E DA CAPITAL E DO NOTÍCIAS E DO PAIZ E DO DIA E DA NAÇÃO E DA REPUBLICA E DA LUCTA E DE TODOS, TODOS OS ARTISTAS DE PORTUGAL QUE EU NÃO GOSTO!" (Negreiros, 2013). E faz piadas com Dantas, gritando ofensas não apenas ao homem profissional, mas também pessoais: "O DANTAS VESTE-SE MAL! O DANTAS USA CEROULAS DE MALHA! ... O DANTAS É UM CIGANÃO! ... O DANTAS NÚ É HORROROSO! O DANTAS CHEIRA MAL DA BOCA!” (Negreiros, 2013). 
Isso teria dividido as opiniões sobre a intencionalidade e, talvez, a seriedade do tal manifesto, surtindo repercussões de todos os tipos: houve quem se divertisse com ele, mas, também, houve quem lhe dedicasse algumas palavras contrárias nos jornais da época. ${ }^{16}$ Decerto que Dantas não surgiria como uma preocupação para Negreiros se tivesse restringido seu discurso ao âmbito médico, mas, sim, no momento em que interfere e atua na produção artística, sendo ele o "expoente máximo do establishment cultural português da época" (Ferreira, 2013, p.39). E, se de alguma forma, sua tese Pintores e poetas de Rilhafoles entra para o interesse das artes, isso se dá no momento em que concebe o alienista como um crítico e a forma estética de muitos artistas de sua época como degenerada. Para melhor entender o conteúdo desse manifesto, é preciso lembrar que Dantas enfatiza o ranço criado com os artistas modernistas ao publicar, em 1915, o artigo "Poetas-paranoicos", na revista Ilustração Portuguesa, defendendo um ataque direto aos poetas da recém-lançada revista Orpheu: ${ }^{17}$

Alguns rapazes, com muita mocidade e muito bom humor, publicaram, há dias, uma revista literária em Lisboa. Essa revista tinha apenas de notável a extravagância e a incoerência de algumas, senão de todas as suas composições. Como a recebeu a imprensa diária? Com o silêncio que merecia? Com as duas linhas indulgentes e discretas que é de uso consagrar às singularidades literárias de todos os moços? Não. A imprensa recebeu essa revista com artigos de duas colunas - na primeira página. A imprensa fez a essa revista um tão extraordinário réclame, que a primeira esgotou-se e já se está a imprimir a segunda. Ora semelhante atitude está longe de ser inofensiva ou indiferente. Em primeiro logar, consagra uma injustiça fundamental; em segundo logar, favorece e prepara uma seleção invertida. Eu bem sei que o reclame a certas obras é às vezes feito à custa da veemente suspeita de alienação mental que pesa sobre os seus autores. Mas n'este caso, como em outros muitos, é justo confessar que os loucos não são precisamente os poetas, mais ou menos extravagantes, que querem ser lidos, discutidos e comprados; quem não tem juízo é quem os lê, quem os discute e quem os compra (Dantas, 19 abr. 1915, p.481).

Voltando a Negreiros, em entrevista concedida em $1965,{ }^{18}$ tem-se claro que o artista não reclamava em seu Manifesto anti-Dantas pelos pintores e poetas de Rilhafoles, mas à suspeita (de Dantas) de alienação mental que pesa sobre os autores de Orpheu. Para o futurista, Dantas usou desmedidamente seus conhecimentos ao expandir sua teoria médica aos artistas modernistas, ao chamar de "paranoico" aquele que não estava internado, que era a promessa do futuro na arte e na literatura portuguesa. E mesmo não citando a tese, é clara a ofensa de Almada, afinal, "Poetas paranoicos" foi publicado em um jornal de grande circulação, diferente da tese Pintores e poetas de Rilhafoles, que, ao contrário do que almejava Dantas, teria ficado restrita ao âmbito médico. Vale lembrar que, para Dantas, em consonância com suas ideias, "paranoico" era aquele indivíduo que teria uma "feição perfeitamente fossil, tornando-o um anachronico em face das ideias de seu tempo e [que] marca com o sello do archaismo todos os productos da sua celebração doente ... D'ahi, o caracter de regressão ideativa e plastica dos documentos d'arte" (Dantas, 1900, p.35). Ou seja, se os poetas de Orpheu são paranoicos, como prevê Dantas, eles estariam registrando em suas obras os resquícios "archeologicos" vindos de "estratificações profundas", sendo, portanto, uns "primitivos" (p.35). Se Dantas tivesse criado sua nosologia médica e a tivesse limitado ao domínio hospitalar, possivelmente não teria ganhado um antimanifesto. Dias antes da publicação de "Poetas paranoicos", o doutor Júlio de 
Matos (30 mar. 1915) havia lançado um artigo no jornal A Capital, intitulado "Litteratura de manicômio: os poetas de Orpheu", e uma entrevista no jornal A Lucta, intitulada "Arte exótica: os poetas de Orpheu e os alienistas" (Matos, 11 abr. 1915). ${ }^{19}$ Na entrevista, Matos diz ainda não ter lido a revista e, após ouvir alguns trechos, tece uma breve análise:

Isso é o que chamamos, em terminologia tecnica, a 'dissociação da personalidade', como se dá com certos doentes atacados de histeria, que durante a crise, escrevem e agem como se fosse sob a inspiração de terceira entidade ... Os do Orpheu são apenas simuladores. É evidente que quem quizer ser estravagante tem de se assemelhar aos loucos (Matos, 11 abr. 1915, p.1).

Em seguida, discorre sobre exemplos do romantismo francês, como Baudelaire e daquilo que chama de "excentricidade". E conclui sem grandes análises: "Os senhores fazem mal em ligar-lhes importância, em fazer-lhes reclame. Isso é o que eles querem. Portanto não são doidos. É escusado ter dó. Podemos rir-nos deles" (Matos, 11 abr. 1915, p.1).

No artigo publicado no jornal A Capital, esse mais analítico - o que demonstra que Matos já tinha lido, sim, a revista -, nomeia um a um os poetas, categorizando-os tal como aqueles que a psiquiatria classificou dentro dos manicômios, apesar de "andar fora d'elles" (Matos, 30 mar. 1915, p.1). E, como homem de ciência, menciona sua fonte áurea, Pintores e poetas de Rilhafoles, para destacar as características degeneradas, as formas taxionômicas, encontradas nos poemas de Orpheu, sejam elas:

A chromofilia, o simbolo, a allegoria, o neologismo, o egocentrismo, a autophilia, a 'linguagem de malhas perdidas, fragmentaria, desconchavada, cheia de lacunas correspondentes a palavra, phrases ou pensamentos inteiros que não tiveram tempo de fixar-se, gafa de vocábulos e detrictos sillabicos reunidos por simples uliterações ou consonancias, ferida, emfim, da incoherencia mais desastrosa e tomando a feição de uma algaravia as vezes brilhante, mas sempre grotesca e tumultuaria' - tudo isso que assignala a arte do paranoico literatto se depara nas produções dos individuos acima citados e nas de outros que collaboram com elles (Matos, 30 mar. 1915, p.1).

Por fim, e como prova de seu acerto, cita alguns poemas de Mario de Sá-Carneiro (18901916) e Álvaro de Campos, entre eles, respectivamente:

Eu não sou eu nem sou o outro,

Sou qualquer coisa de intermédio:

Pilar da ponte de tédio

Que vai de mim para o Outro.

(Lisboa - Fevereiro de 1914.)

Nem sei que existo para dentro. Giro, rodeio, engenho-me.

Engatam-me em todos os comboios.

Içam-me em todos os cais.

Giro dentro das hélices de todos os navios.

Eia! eia-hô! eia!

Eia! sou o calor mecânico e a electricidade!

(1914, Março - No Canal de Sués, a bordo.)

(Matos, 30 mar. 1915, p.1). 
Sobre este último, Matos diz ser o único com versos mais claros, distanciando-se, com efeito, "dos confrades e a sua authentica paranoia, em que a influência do chamado futurismo é evidente" (Matos, 30 mar. 1915, p.1). Vale ainda lembrar o fato de Álvaro de Campos ser um dos heterônimos de Fernando Pessoa, o que torna os elogios de Matos mais controversos ou mais irônicos; afinal, não seria esse um sinal de "egocentrismo", uma das características da paranoia? Ambos os autores citados tinham fortes tendências ao simbolismo, ou, mais ainda, ao que Pessoa chamará, em um texto de 1916, de "sensacionismo", ao tratar desses dois poetas:

O sensasionismo teve início com a amizade entre Fernando Pessoa e Mário de SáCarneiro. É provavelmente dificil separar a parte que cabe a cada um na origem deste movimento, e certamente inútil derterminá-lo ... Nenhum sensacionista foi mais além do que Sá-Carneiro na expressão do que em sensacionismo se poderá chamar sentimentos coloridos. A sua imaginação - uma das mais puras na moderna literatura ... - corre desenfreada por entre os elementos que os sentidos lhe facultaram, e o seu sentido da cor é dos mais intensos entre os homens de letras (Pessoa, 1966, p.140). ${ }^{20}$

E, de fato, Sá-Carneiro foi além de todos eles, levando a cabo as sensações de seus poemas ao suicidar-se (aos 26 anos de idade) com cinco frascos de estricinina. Nas palavras do pesquisador Urbano Tavares Rodrigues (1973, p.20):

A obsessão do suicídio é nele como uma lepra dos nervos, uma oculta chaga que supura nas últimas cartas, as de $1916 \ldots$ sente-se enlouquecer, despreza-se, já nem se acha interssante, não se esforça sequer por o ser aos próprios olhos, desdenha até a sua mormidez, falecem-lhe as derradeiras resistências ao fastio.

O suicídio de Sá-Carneiro seria a prova de que os artigos "anti-orphistas" de 1915 eram certeiros nas análises que propunham: tratava-se de poetas degenerados. Tanto Matos quanto Dantas previam que a decadência estética levava à decadência política e social, pois era o resultado avançado da degeneração mental e física. Matos não foi alvo direto dos futuristas, como o foi Dantas, talvez por ter se limitado a sua profissão de médico e alienista, deixando as letras e as artes para outros interessados. Se escreve essas palavras no jornal, não é na figura de um crítico - como parecia almejar Dantas -, mas, na figura única de um alienista preocupado com os rumos da mentalidade social. Fato é que - e o propósito deste artigo foi tornar isso visível - se Dantas é "a meta da decadência mental" (Negreiros, 2013), como o talha Negreiros em seu manifesto, ele não o é sozinho: sua mentalidade é o produto de uma época e de conteúdos apreendidos pelo saber médico.

É preciso lembrar, e isso já se faz tarde, que Dantas, ao mesmo tempo que se formava médico, estudava literatura e história das artes. Por volta de 1900, publicara um livro de poesias e duas peças de teatro, e, mais tarde, estendera tal produção a diversas peças e prosas. Em 1916, quando Almada em tom vociferante lançou seu manifesto, Dantas já era um literato reconhecido, admirado por parte da intelectualidade portuguesa e do tipo que tudo sabia e tudo queria saber, tal como trata seu biógrafo Luís de Oliveira Guimarães (1963, p.44-45):

o certo é que a medicina, a mais 'humana' de todas as profissões, tem, como a arte, por objeto 'o homem total'; para ser um grande clínico, como para ser um grande escritor, torna-se preciso antes de tudo (já dizia Claude Bernard) 'possuir imaginação criadora'. 
Dantas perseguiu esse desejo de conceber as várias áreas até seus últimos dias: "Aos vinte e três anos formei-me em medicina; cinquenta e quatro anos depois, sou doutorado em Letras. Parti cheio de fé para um determinado ponto, cheguei a outro, completamente diferente. Quer dizer: errei a vida toda" (Dantas citado em Guimarães, 1963, p.55). E o que seria o acerto para Dantas (as letras) era, já em 1916, o erro para Negreiros: "O DANTAS SABERÁ GRAMMÁTICA, SABERÁ SYNTAXE, SABERÁ MEDICINA, SABERÁ FAZER CEIAS P'RA CARDEAIS, SABERÁ TUDO MENOS ESCREVER, QUE É A ÚNICA COISA QUE ELLE FAZ!" (Negreiros, 2013). É verdade que Dantas se envolvia com diversos temas. Basta observarmos a "tábua de matérias" do livro Discursos (Dantas, 1943), onde se vê que o médico literato falava sobre tudo, havendo discursos sobre os mais variados temas: língua portuguesa, Montaigne, Victor-Hugo, Galileu, história portuguesa, Academia Brasileira de Letras, e isso é só para citarmos alguns deles. Dantas buscava compreender o "homem total".

Reconhecia, sobretudo, a importância da medicina em sua carreira literária: "Porque em mim próprio reconheço o quanto valem os estudos médicos e paramédicos na formação mental do escritor" (Dantas, 1925). As questões médico-sociais e profiláticas rondavam, notadamente, seus escritos e poesias, e foram observadas pelo crítico e linguista alemão Wilhelm Giese (1895-1990) como sendo um estilo próprio de Dantas ao tratar de temas como patologias hereditárias e degeneração "sob o ponto de vista científico" (Giese, 1937, p.4). Temas que sorrateiramente Dantas introduziu em seus versos: "A pequena poesia intitulada 'Vida simples' aconselha a vida retirada, longe do bulício do mundo, em ligação estreita com a terra e com a natureza" (p.4):

Ter um canto de terra ou cortinhal:

Por minhas mãos lavrar a terra dura;

Beber um leite bom, uma água pura;

Vestir de burel rude ou de saial...

Viver livre de enganos, socegado,

Vendo os olhos piedosos dos cordeiros,

Que mais faltam à alma que os da gente.

Se à primeira vista o poema não parece ter uma relação direta com a veia científica de Dantas, Giese (1937, p.5-6) afirma, logo em seguida, que há um pessimismo em sua poesia que só poderia vir de um "médico escritor", mas que tal fenômeno é passageiro, considerando que seus textos futuros pretendem mais a interpretações estéticas de temas históricos. Anos antes das considerações de Giese, Fidelino Figueiredo (1888-1967) ${ }^{21}$ emitiu seu parecer no livro $O$ senhor Júlio Dantas, avaliando seus primeiros trabalhos como um "modismo literário", agarrado ao cientificismo e a uma "complicada machinaria de neologismos da terminologia scientífica" (Figueiredo, 1919, p.20). Esse "modismo literário", conforme Figueiredo, seria decorrente de

primitiva educação escolar e litteraria ... constituindo assim um dominante ponto de vista, sempre do médico materialista um pouco suggestionado pela superstição scientífica, sobretudo de certas modernas conclusões suas, a hereditariedade, a degeneração, e os estigmas criminológicos (p.14). 
Porém, é sobretudo com a máxima de conhecer o "homem total" que Dantas estende seus conhecimentos médicos para a sociedade e para as artes em geral. A loucura tinha para ele o caráter de desfecho social, ou seja, era por meio das expressões dos loucos que via a sociedade definhar-se. O tema não era, como demonstramos, de caráter exclusivo de Dantas; a degeneração de um povo entrava, certamente, como questão corrente na época, e, surpreendentemente ou não, aparece no caloroso Ultimatum futurista, de 1917, de Almada Negreiros (194-): ${ }^{22}$

Porque o aspecto geral dos tipos exala um extertor a podre. Portugal, uma resultante de todas as raças do mundo, nunca conseguiu a vantagem de um cruzamento útil porque as raças belas isolaram-se por completo. Exemplo: as varinas. O português, como os decadentes, só conhece os sentimentos passivos: a resignação, o fatalismo, a indolência, o medo do perigo, o servilismo, a timidez, e até a inversão. Quando é viril manifestase instintivamente animal a par do seu analfabetismo primitivamente anti-higiénico.

Almada critica Dantas por seu atraso e conservadorismo, mas, de todo modo, ele próprio também é um homem de sua época: um visionário da formação nacional, da modernização, do futuro glorioso, da raça forte e do patriotismo. O que separa Dantas de Almada é, em especial, a concepção estética da política, visões de mundo que só podiam se encontrar para o embate. De um lado, o mundo concebido pela conservação das formas, pelo diagnóstico e pelo soneto bem acabado, de outro, pela distorção das formas, pelo experimentalismo e pela sátira.

Em contraposição às críticas dos modernistas, Dantas manteve-se poeta, dramaturgo e literato até sua morte. Em 1950, o discurso do jurista e político José Caeiro da Matta (18771963), em homenagem ao "diplomata e homem de Estado", ${ }^{23}$ lembra que Dantas possui vários talentos (da medicina à política), mas, acima de tudo, o literário:

já então escritor de renome internacional, que atingira a suprema perfeição literária, é levado um dia a fazer ceder sua personalidade literária pela personalidade política. Realiza como ministro uma obra notável. É aclamado, é exaltado. Mas não se prende por muito tempo a esta nova fisionomia da sua vida. Chamam-no os seus antigos amores. Mais do que nunca o atrai a vida do pensamento, o refúgio tranquilo e aliciante das letras (Matta, 1950, p.8).

Tudo isto para mostrar que as críticas de Almada a Dantas foram categóricas no intuito de criar uma barreira entre o "velho" e o "progresso". Mas a crítica de Almada não feriu o homem na sua totalidade, pois Dantas era muitos: era o médico, o alienista social, o poeta, o dramaturgo, o contista, o político, o crítico. Dantas e Almada tornaram-se as imagens do "atraso" e do "avanço" português, e encenaram uma batalha que acabou por dividir os modernos lusitanos. Enquanto Almada vociferava "CONTRA TODOS QUE SÃO POLÍTICOS E ARTISTAS" (Negreiros, 2013), Dantas era chamado por Henrique Lopes de Mendonça (1923, p.5) ${ }^{24}$ de "mago das letras ... o mais poderoso agente expansivo do génio português no mundo espiritual moderno".

Como bem nota Sara Afonso Ferreira (2013, p.43) em seu estudo sobre o Manifesto antiDantas, são "inúmeras as referências jocosas a Júlio Dantas" encontradas nas correspondências entre Fernando Pessoa e Mário de Sá-Carneiro, já que Dantas virou assunto nacional. Fato 
é que se o médico literato era tão mencionado - mesmo para afirmar que ele não era um escritor - é porque incomodava muitos, o que parece bem claro nas palavras de Fernando Pessoa a William Bentley:25

outros são de caráter tão fraco e inferior que é um insulto mencioná-los. Neste caso, estão as produções do Sr. Julio Dantas. Dantas não escreve literatura, e sua atitude, quer as do passado ou qualquer outra, não possui importância nenhuma; a melhor coisa que pode ser feita por ele é supor que ele não exista. Mencioná-lo em um jornal de literatura portuguesa é acusar-se de incompetência e incapacidade crítica (Pessoa, 1999, p.196).

Para fazer vingar futurismos, era preciso matar o atraso: "MORRA O DANTAS, MORRA! PIM!" (Negreiros, 2013). Dantas era notícia para o bem ou para o mal, e a demonstração de seu interesse por tais críticas pode ser retirada de sua nota autobiográfica precocemente redigida em 1925:

Dizem que tenho inimigos: é natural que assim seja; pela minha parte não tenho interesse algum em o contestar. Desgraçado de quem não conta, pelo menos, um inimigo ou dois na vida! Mas se há muito quem, no uso dum direito legítimo, tenha criticado, com violência e com paixão, a minha obra, não há ninguém que tenha conseguido perturbar a minha perfeita serenidade. Porque não me merecem toda a minha consideração os meus críticos? Não. Por uma razão mais forte ainda: porque não tenho tempo para os ler (Dantas, 1925).

\section{Considerações finais}

Da mesma forma que Dantas não tinha tempo para ler seus críticos, atualmente são poucos os que têm tempo para ler Dantas. Há que se lembrar que, de acordo com suas teorias, Júlio Dantas viu a sociedade degenerar-se - afinal, venceram as estéticas modernistas de todos os tipos. E a história mostra que os artistas de Orpheu tornaram-se, como se previa, o futuro do modernismo português, e, hoje, o doutor Dantas é recordado, nas referências sobre a revista, como o exemplo máximo do conservadorismo daquele tempo. Sobre os pintores e poetas de Rilhafoles, estes ficaram esquecidos na história, pois não participaram da grande safra dos modernistas; seus versos e seus desenhos mantiveram-se - para o deleite de Dantas - negligenciados como "obras de arte", encerrando essa história como desvios degenerativos da mente.

\section{AGRADECIMENTO}

Finaciado pelo Programa de Doutorado Pleno no Exterior da Coordenação de Aperfeiçoamento de Pessoal de Nível Superior.

\section{NOTAS}

${ }^{1}$ O Hospital Psiquiátrico de Rilhafoles foi fundado em 1848, em Lisboa. Ficou conhecido pela posição de pesquisa e inovação que seus diretores e funcionários assumiram. Em 1911, passou a se chamar Hospital Psiquiátrico Miguel Bombarda; fechou em 2010, e seus últimos pacientes foram transferidos para outras instituições do país.

${ }^{2}$ Miguel Bombarda tornou-se conhecido pelo trabalho político que desenvolveu em Rilhafoles, criando métodos alternativos de tratamento e defendendo o livre acesso aos benefícios da ciência e da saúde. Ativista político, brigou pela causa republicana em oposição à conjuntura monarquista, declarando-se socialista e anticlerical. Dois dias antes da Revolução de 5 de Outubro, que instaurou a República portuguesa, foi assassinado em seu gabinete por um de seus pacientes. Para mais dados de sua biografia, consultar Araújo (2007). 
${ }^{3}$ Todas as citações deste artigo serão mantidas no português da época para que não se perca nenhum sentido original. Isto porque muito do conteúdo analisado só pode ser compreendido numa linguagem datada e regional.

${ }^{4}$ Sobre a produção literária e a biografia de Dantas, consultar Guimarães (1963); Figueiredo (1919); Dantas (1925); e Giese (1937).

${ }^{5}$ José Luís Rodrigues Cebola Júnior (1876-1967) foi diretor da Casa de Saúde do Telhal, em Sintra, entre 1911 e 1948. Assim como Dantas, e em paralelo com a sua atividade como médico psiquiatra, publicou uma série de obras literárias e, como Bombarda, foi um atuante político da causa republicana. Sobre Cebola e sua produção, ver Pereira (2014).

${ }^{6}$ Após o fechamento do Hospital Miguel Bombarda, em 2010, seu arquivo e seu acervo ficaram sob a responsabilidade da administração do Centro Hospitalar Psiquiátrico de Lisboa; contudo, boa parte da coleção de obras reunida por Bombarda, a qual preferimos chamar de "documentação", desapareceu com o tempo.

${ }^{7}$ Ales Hrdlicka foi um antropólogo difusionista que criou teorias acerca da origem do homem, seu grande foco de pesquisa.

${ }^{8}$ Algumas das principais publicações sobre o tema nesse período foram: Forbes Winslow, On the insanity of men of genius (1848); Abroise Tardieu, Études médico-légale sur la folie (1872); Césare Lombroso, Genio e follia (1872); Max Simon, L'imagination dans la folie: étude sur les dessins, plans, descriptions et costumes des aliénés (1876). Uma série de outras publicações surge após 1900; a mais conhecida delas é de autoria de Hans Prinzhorn, Bildnerei der Geisteskranken: ein Beitrag zur Psychologie und Psychopathologie der Gestaltung (1922), que muito influenciou artistas como Paul Klee, Max Ernst, Jean Dubuffet e Kandinsky (ver Macgregor, 1989, p.292).

${ }^{9}$ A teoria da degeneração foi muito difundida e praticada desde a publicação do Traité de dégénérescences physiques, intellectuelles et morales de l'espèce humaine et des causes qui produisent ces variétés maladives de Benedict August Morel, em 1857.

${ }^{10}$ Bombarda continua seu discurso na intenção de mostrar que Portugal entrou nesse sentido de civilização ao criar o Hospital de Rilhafoles, em Lisboa, e o Hospital Conde Ferreira, no Porto, mas atesta que isso ainda era pouco, considerando os números que compunham os cuidados com os alienados em outros países, como a Alemanha.

${ }^{11}$ A ideia de que a família e a sociedade deviam ser cultivadas com devida precaução, evitando a transmissão de genes defeituosos e degenerativos, fundamenta-se na ciência eugênica do inglês Francis Galton (18221911), prevendo práticas de conteção das enfermidades hereditárias, tais como alcoolismo, homossexualismo, doenças venéreas, insanidade, entre outras.

${ }^{12}$ Nos termos de Michel Foucault, o Estado moderno, no seu processo de formação, institui como modelo de funcionamento para o desenvolvimento capitalista a biopolítica normativa. Nesse modelo, prevê-se que: "O homem ocidental aprende pouco a pouco o que é ser uma espécie viva num mundo vivo, ter um corpo, condições de existência, probabilidade de vida, saúde individual e coletiva, forças que se podem modificar, e um espaço em que se pode reparti-las de modo ótimo. Pela primeira vez na história, sem dúvida, o biológico reflete-se no político; o fato de viver não é mais esse sustentáculo inacessível que só emerge de tempos em tempos, no acaso da morte e de sua fatalidade: cai, em parte, no campo de controle do saber e de intervenção do poder" (Foucault, 1988, p.128). Podemos, portanto, considerar que a institucionalização psiquiátrica emana desse processo por prever o controle da espécie humana em nome de políticas de Estado, a partir de uma série de instrumentos de biopolítica, ou seja, de ferramentas que docilizam os corpos e atuam sobre a vida em sociedade.

${ }^{13}$ Júlio de Matos foi o segundo diretor do Hospital Miguel Bombarda, entre 1911 e 1922.

${ }^{14} \mathrm{O}$ doutor Júlio de Matos (1884, p.15-16), em seu Manual das doenças mentais, já tinha sobre as expressões dos alienados semelhantes considerações: "Às vezes destacamse da craveira comum das inteligências, excedendoa muito entretanto as suas aptidões são sempre exclusivas e restritas. Uns são bons poetas, outros bons músicos ou bons pintores mas nenhum possui a maleabilidade de espírito que uma educação enciclopédica reclama e exige".

${ }^{15}$ José de Almada Negreiros começou a carreira artística fazendo desenhos humorísticos para jornais entre 1911 e 1912, participando neste último ano da Primeira Exposição do Grupo de Humoristas. A amizade com Fernando Pessoa inicia-se em 1913, sendo convidado a participar do primeiro e do segundo volumes da Revista Orpheu, já como poeta. Mas, de fato, Negreiros destacou-se mais nas artes visuais do que nas poéticas, sendo um entusiasta do movimento futurista e criador do Ultimatum futurista. Para mais informações sobre sua trajetória biográfica e artística sugere-se a leitura de Almada: o português sem mestre (França, 1974). 
${ }^{16}$ A pesquisadora Sara Afonso Ferreira menciona - na análise feita para a edição fac-símile do Manifesto algumas dessas opiniões, citando Amadeu de Souza Cardoso, em carta a Robert Delaunay: "O manifesto de Negreiros é muito com e muito português"; como também, a crítica de Albino Forjaz de Sampaio escrita para o jornal A Lucta, em 28 de junho de 1915: “O sr. Almada Negreiros é um mocinho ansioso de popularidade. Como até agora a sua hora não tenha chegado, publicou uma coisa a que chamou 'Manifesto anti-Dantas ...'. A uns insulta, a outros deprime e a alguns desopila ... Alguns dos argumentos anti-Dantas são que ele usa ceroulas de malha. Achamos péssimo que se traga para o público as decepções amorosas de cada um" (Ferreira, 2013, p.38).

${ }^{17}$ A revista Orpheu marcou o modernismo português. O primeiro volume, de março de 1915 , foi dirigido e editado por Fernando Pessoa e Mário de Sá-Carneiro, com prefácio de Luis de Montalvor: "Nossa pretenção é formar, em grupo ou ideia, um número escolhido de revelações em pensamento ou arte, que sobre este princípio aristocrático tenham em Orpheu o seu ideal esotérico e bem nosso de nos sentirmos e conhecermonos" (Montavôr, 1989, p.5). O segundo volume foi editado no mesmo ano, e o terceiro teve apenas provas de tipografia, sendo publicado apenas em 1984. Trata-se, essencialmente, de uma revista de poesia, com alguns trabalhos visuais de Santa Rita-Pintor no segundo volume. Seus colaboradores: Fernando Pessoa e seu heterônimo Álvaro de Campos, Mário de Sá-Carneiro, Luis de Montalvôr, Almada Negreiros, Alfredo Pedro Guisado, Côrtes Rodrigues, Ângelo de Lima, Raul Leal, Eduardo Guimarães e Violante de Cysneiros. Vale lembrar que Ângelo de Lima era interno do Hospital de Rilhafoles e foi citado na matéria publicada em 1902 "Miséria em Lisboa", ao tratar da "colecção" de obras organizada por Miguel Bombarda.

${ }^{18}$ A entrevista radiofônica pode ser ouvida no CD que acompanha a edição fac-símile do Manifesto anti-Dantas (ver Ferreira, 2013). Almada cita, nessa entrevista, um inquérito que teria sido feito pelo jornal A Capital, no qual se perguntou aos médicos psiquiatras Júlio de Matos, Egas Moniz e Júlio Dantas se os poetas de Orpheu seriam mesmo loucos. Conforme Almada, a resposta positiva teria vindo apenas de Júlio Dantas. Contudo, esse inquérito nunca foi localizado, e, conforme bem nota Sara Afonso Ferreira, parece ter sido inventado pela personalidade teatral de Almada Negreiros.

${ }^{19}$ Essa entrevista é realizada com dois "ilustres psiquiatras portuguezes"; o primeiro, a seu pedido, não tem o nome divulgado, mas especula-se que tenha sido Egas Moniz, pela descrição apresentada no próprio jornal, e o segundo é Júlio de Matos. O psiquiatra anônimo tece análises muito próximas às de Matos, dizendo que se trata de "meninos sem talento que querem chamar sobre si as atenções do público vomitando asneiras ... É a sua originalidade. E todos fazem um simbolismo idiota e grotesco, sem elevação nem critério. Perguntam-me se são produções degeneradas. Nada disso. Esses escreveriam melhor. Querem chamar sobre si o escândalo, mas nem isso conseguem" (Matos, 11 abr. 1915, p.1).

${ }^{20}$ Nessa e nas demais citações em língua estrangeira, a tradução é da autora.

${ }^{21}$ Fidelino Figueiredo foi um estudioso e crítico de literatura portuguesa.

${ }^{22}$ Manifesto futurista, escrito por José de Almada Negreiros.

${ }^{23}$ Discurso proferido na sessão em honra de Júlio Dantas, em 4 de março de 1950. De tudo, faltou mencionar que Dantas assumiu diversos papéis na política: foi deputado durante o período monárquico e ministro na Primeira República, além de deputado e presidente da Comissão dos Centenários e embaixador no Estado Novo (ver Guimarães, 1963).

${ }^{24}$ Escritor e um dos presidentes da Academia das Sciencias de Lisboa.

${ }^{25}$ William Bentley foi editor da revista Portugal: a Monthly Review of the country, its colonies, commerce, history, literature and art (ver Ferreira, 2013, p.45).

\section{REFERÊNCIAS}

ANDRIOLO, Arley.

O método comparativo na origem da psicologia da arte. Revista Psicologia USP, v.17, n.2., p.43-57]. Disponível em: http://www. scielo.br/scielo.php?script=sci_arttext\&pid =S0103-65642006000200003. Acesso em: 7 mar. 2016. jun. 2006.

ARAÚJO, Paulo.

Miguel Bombarda: médico e político. Editora:

Caleidoscópio. 2007.
BOMBARDA, Miguel.

Hospital de Rilhafolles: civilisação e assistência dos alienados. Revista Brasil Portugal, n.20, p.3. 1899.

BOMBARDA, Miguel.

A consciência e o livre arbítrio. Lisboa: Livraria de António Maria Pereira. 1898.

CEBOLA, Luiz.

A mentalidade dos epilépticos. Setubal: Typografia de J.L. Santos \& Com. 1906. 
DANTAS, Júlio.

Discursos. Lisboa: Bertrand. 1943.

DANTAS, Júlio.

Julio Dantas: a sua vida e a sua obra. Lisboa: Empreza do Diário de Notícias. 1925.

DANTAS, Júlio.

Poetas paranoicos. Ilustração Portuguesa, $2^{\mathrm{a}}$ série, n.478, p.481. 19 abr. 1915 .

DANTAS, Júlio.

Pintores e poetas de Rilhafolles: estudos sobre as manifestações artísticas em certas psicóses. Lisboa: Guimarães, Libano \& Cia. 1900.

DANTAS, Júlio; PENTEADO, Manoel.

Doentes: estudos. Porto: Graphia Occidental. 1897.

EARLE, Pliny.

The poetry of insanity. In: American Journal of Insanity, 2. UTICA: Printed by Bennett, Backus, Hawley, 1844.

FERREIRA, Sara Afonso (Org.).

Manifesto anti-Dantas e por extenso: por José de Almada Negreiros poeta d'Orpheu futurista e tudo! Lisboa: Assírio \& Alvim. 2013.

FIGUEIREDO, Fidelino.

O senhor Júlio Dantas. Lisboa: Clássica. 1919.

FOUCAULT, Michel.

História da sexualidade, 1: a vontade de saber. Rio de Janeiro: Graal. 1988.

FRANÇA, José Augusto.

Almada: o português sem mestre. Lisboa: Estúdios Cor. 1974.

GIESE, Wilhelm.

Aspectos da obra literária de Júlio Dantas. Coimbra: Biblioteca da Universidade. 1937.

GUIMARÃES, Luís de Oliveira.

Júlio Dantas: uma vida, uma obra, uma época.

Lisboa: Romano Torres. 1963.

MACGREGOR, John. M.

The discovery of the art of the insane. New Jersey: Princeton University Press. 1989.

MATOS, Julio de.

Arte exotica: os poetas do Orpheu e os alienistas. A Lucta, p.1-2. 11 abr. 1915.

MATOS, Julio de.

Litteratura de manicomio: os poetas do Orpheu. A Capital, p.1. 30 mar. 1915.

MATOS, Julio de.

Manual de doenças mentais. Porto: Livraria Cultural de Campos \& Godinho Editores. 1884.

MATTA, José Caeiro da.

Júlio Dantas: diplomata e homem de Estado. Lisboa: Academia de Ciência de Lisboa. 1950.
MENDONÇA, Henrique Lopes.

Julio Dantas: esboço de perfil literário. Lisboa: Companhia Editora. 1923.

MISÉRIA...

Miséria em Lisboa. O Dia. p.2. 5 set. 1902.

MONTAVÔR, Luis de.

Orpheu volume 1. Edição fac-similada. Lisboa:

Contexto, 1989.

NEGREIROS, Almada.

Ultimatum Futuristas às gerações portuguesas do século XX. Coleção Documentos Literarios (Biblioteca Nacional de Lisboa, Lisboa). 194-.

NEGREIROS, José de Almada.

Manifesto anti-Dantas e por extenso: por José de Almada Negreiros poeta d'Orpheu futurista e tudo! In: Ferreira, Sara Afonso (Org.). Manifesto anti-Dantas e por extenso por José de Almada Negreiros poeta d'Orpheu futurista e tudo! Lisboa: Assírio Alvim. 2013.

PEREIRA, Ana Leonor

A institucionalização da loucura em Portugal. Revista Crítica de Ciências Sociais, n.21, p.85-99. 1986.

PEREIRA, Denise M. Borrega.

Quando desci ao inferno. Um retrato ideológico, clínico e moral da loucura pelo psiquiatra Luís Cebola (1876-1967) em meados do século XX. Revista (In)visível, edição 2, p.21-32. 2014.

PESSOA, Fernando.

Correspondências 1905-1922. Lisboa: Assírio \& Alvim. 1999.

PESSOA, Fernando.

Páginas íntimas e de auto-interpretação. (Textos estabelecidos e prefaciados por Georg Rudolf Lind e Jacinto do Prado Coelho). Lisboa: Ática. 1966.

QUINTAIS, Luís.

Torrente de loucos: a linguagem da degeneração na psiquiatria portuguesa da transição do século XIX. Revista História, Ciências, SaúdeManguinhos, v.15, n.2, p.353-369. Disponível em http://www.scielo.br/scielo.php?script=sci_arttex t\&pid=S0104-59702008000200007. Acesso em: 7 mar. 2016. 2008.

RODRIGUES, Urbano Tavares.

Prefácio. In: Rodrigues, Urbano Tavares. Cartas a Fernando Pessoa. Lisboa: Edições Ática. p.9-22. 1973.

SIMON, Paul-Max.

L'imagination sur la folie. Paris: Imprimerie de E. Donnaud, 1876.

TARDIEU, Ambroise.

Études médico-légales sur la folie. Paris: Librairie J.-B. Bailliere et Fils. 1880.

WINSLOW, Forbes.

Mad artists. Journal of Psychologial Medicine and Mental Pathology, n.s.6. 1848. 